
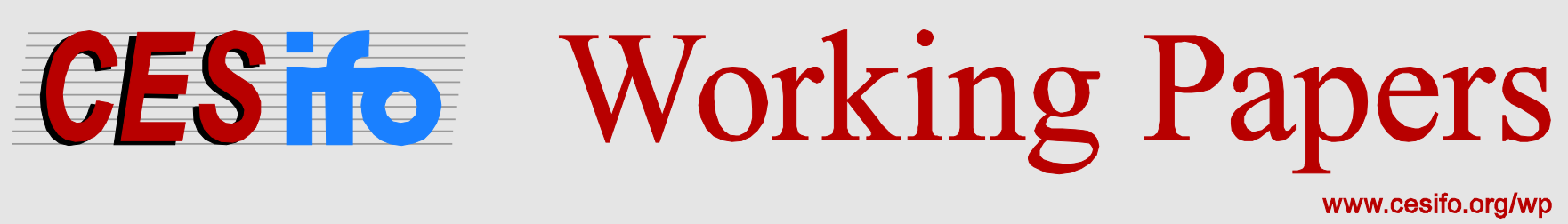

\title{
Subsidizing Health-Conscious Behavior Now or Later
}

\author{
Kamila Danilowicz-Gösele \\ Robert Schwager
}

\author{
CESIFO WORKING PAPER NO. 5734 \\ CATEgORY 1: PUBlic FinANCE \\ JANUARY 2016
}
An electronic version of the paper may be downloaded
- from the SSRN website:
- from the RePEc website:
- from the CESifo website:
www.SSRN.com
Www.RePEc.org
www.CESifo-group.org/wp




\title{
Subsidizing Health-Conscious Behavior Now or Later
}

\begin{abstract}
In a model where consumers have quasi-hyperbolic preferences, we compare immediate subsidies paid for health-conscious consumption and future subsidies rewarding good health outcome. We characterize the subsidy rates which implement the unbiased choice. These rates differ because of two countervailing effects: (1) the individual applies quasi-hyperbolic discounting to future subsidy receipts, and (2) she can use the future subsidy to partially correct her own future behavior. We further show that future subsidies result in higher costs for a government which discounts exponentially. However, this result does not necessarily hold if the government itself is formed by time-inconsistent individuals.
\end{abstract}

JEL-codes: H310, D910, I180.

Keywords: present-bias, quasi-hyperbolic discounting, paternalism, health.

Kamila Danilowicz-Gösele

Chair of Public Economics

Georg-August University Göttingen

Göttingen / Germany

kdanilo@uni-goettingen.de
Robert Schwager*

Chair of Public Economics

Georg-August University Göttingen

Göttingen / Germany

rschwag@uni-goettingen.de

*corresponding author

January 2016 


\section{Introduction}

Life consists of three cycles - past, present and future. We regret our past, fully appreciate the present pleasures and very often refuse to move forward. Sometimes there is not even an inch of movement, and although we consistently plan to direct our behavior towards the future, currently the most immediate moment still gets the highest weight. This so-called present-bias is reflected in the popular saying - Eat, drink and be merry, for tomorrow we diet. According to that saying, people either underestimate the effect of today's consumption on future health or postpone health investments to a later date, since unpleasant activities seem to be even more unpleasant the closer they are to the present. As a consequence, a well-meaning paternalistic government may intervene to counterbalance the intertemporal distortion of consumption toward the present and hence improve the health status.

In this paper we analyze a specific instrument for this intervention, health-related subsidies. These can be designed in two different ways, depending on the timing and the target of the subsidy. They can either immediately reward an individual's healthconscious consumption, or reward the individual's health outcome in the future. We show that this distinction is relevant both for the determination of the optimal subsidy rate and for the subsidy's effectiveness, measured by the tax revenues required to overcome the present-bias. This is due to the fact that an immediate and a future subsidy are paid to different 'selves' of the individual.

Apart from subsidies, taxes on unhealthy behavior, so-called 'sin taxes', come to mind as an alternative instrument to overcome present-biased behavior. Indeed, from a public finance point of view, taxes may appear as the superior instrument since they have the obvious advantage of raising revenues. Consequently, research on paternalistic interventions has so far mostly concentrated on taxes. Nevertheless, subsidies are also widespread, as the examples below illustrate. The reason for this fact may be that rewarding (with subsidies) has more positive connotation than punishing (with taxes):

giving instead of taking away. In particular, a government which would create incentives for healthy consumption by taxing the sick would be considered nasty and inhuman, even if the individuals themselves have triggered the illness by their own behavior.

For these reasons, we study health-related subsidies. We begin, in Section 2, with some examples of immediate and future health subsidies, followed by a brief review of the literature related to paternalistic policies. Our analysis is based on a model, presented in Section 3, of an infinite-horizon consumer choice problem with two goods 
per period. In addition to a numeraire good, there is a healthy good that creates positive health consequences in the future in addition to current utility from consumption. Present-bias is modeled in the form of quasi-hyperbolic discounting as in Harris and Laibson (2001).

We consider a government which treats such short-time desire as an error and hence intervenes to correct the individual's choices. In Section 4, we analyze an immediate subsidy paid for health-conscious consumption in the same period and a future subsidy rewarding a good health outcome one period later. For both forms of subsidy, we characterize the rate which, despite present-biased preferences, induces the consumption pattern which an unbiased individual would choose. While the optimal rate of immediate subsidy simply bridges the gap between the biased and the unbiased evaluation of health benefits, the future subsidy must take into account two behavioral responses of the individual which are specific to present-biased preferences. On the one hand, future transfer income, just like future health, is valued less by the individual - the discounting effect of the future subsidy. On the other hand, the individual can change the behavior of her future self by increasing future income - the instrumental effect of the future subsidy.

In a next step, in Section 5, we investigate how the balance of these effects determines the present value of taxes required to finance the optimal subsidy. From the point of view of a paternalistic decision maker, who discounts future payments in an unbiased fashion, the immediate subsidy entails lower cost since the discounting effect dominates. This result suggests that policies of the second kind, where the reward is delayed, are less effective in the presence of present-biased preferences than policies of the first kind, where health conscious behavior is subsidized immediately.

Finally, in Section 6, we abandon the assumption of a paternalistic government, and instead consider a government which represents the individual. This government follows the same present-biased preferences as the consumer, but has the same fiscal instruments at its disposal as the paternalistic government. We show that such a government implements the optimal subsidy only if it puts sufficiently high weight on future payoffs. Otherwise, the gain from committing future selves to increased healthy consumption does not outweigh the immediate loss from forcing an unwanted change in behavior upon one's own current self. Furthermore, since a present-biased government discounts future tax payments more heavily, the cost of future subsidies counts for less in its evaluation of present values than in the computation of a paternalistic government. Therefore, in contrast to the paternalistic government, the government which represents 
the consumer will in some cases favor the future over the immediate subsidy scheme. We conclude in Section 7 by summarizing our findings and suggesting possible extensions of our analysis.

\section{Examples and Literature}

An example for an immediate subsidy is provided by a new nutrition program, Healthy Incentives Pilot (HIP), developed by the United States Department of Agriculture, which has been tested for 12 months in Hampden County (Massachusetts). ${ }^{1}$ HIP is an incentive-based program to empower low-income people, Supplemental Nutrition Assistance Program (SNAP) recipients, to consume more fruits and vegetables. For every dollar spent with the SNAP Electronic Benefit Transfer cards on fruit and vegetables, participants earned an incentive of 30 cents. The incentive was immediately added to their SNAP account, thus cutting the costs for fruit and vegetables by almost one third. According to the final report, HIP participants increased their consumption of targeted fruits and vegetables by $26 \%$, driving the Healthy Eating Index by $5 \%$. The self-reported total spending on fruits and vegetables of HIP households was $8.5 \%$ higher than spending reported by non-HIP households, and stayed stable across the pilot period.

Another example is the School Fruit Scheme (SFS), an EU-wide voluntary program designated to encourage young people to consume more fruit and vegetables. ${ }^{2}$ According to the final report (see European Commission, 2015), in 2010/11 SFS reached $8,146,290$ children in 54,267 schools. The program thus proved successful in increasing the fruit and vegetables consumption of children in the short-run. Further examples for immediate subsidies are financial rewards for abandoning unhealthy behaviors (see Volpp et al. (2008), Volpp et al. (2009)) and pricing and promotion strategies related to healthy items (see French et al. (2001)).

There are also examples for programs where the reward is given after a certain period of time. In the United States, many companies offer Healthy Rewards Cards and other rebate programs as an incentive to promote healthy lifestyles. Participants of health reward programs earn points and gift cards for engaging in healthy behaviors such as quitting tobacco (IBM: "Healthy Living Rebate" program), participating

\footnotetext{
${ }^{1}$ See Bartlett et al. (2014).

${ }^{2}$ Participating Member States are in addition required to implement strategies including educational and awareness-raising initiatives.
} 
in disease management programs (FedEx: diabetes-management program; IBM: childhood obesity management program "Children's Health Rebate"), taking the general health assessments or exercising regularly (Scotts Miracle-Gro: "Health Quotient" and "Wellness Center"). ${ }^{3}$

Also in Germany future subsidies in form of bonus programs offered by statutory health insurance companies are a part of modern life. Finally, an example for a subsidy on future health outcomes is provided by the widespread use, in health insurance contracts, of rebates granted to clients who do not claim any expenses during some period. These examples show that health-related subsidies are a widely used and effective policy instrument.

In public finance research, present-biased preferences and paternalistic policies to improve individual decision making have received increasing attention. O'Donoghue and Rabin $(2003,2006)$ study optimal sin taxes in an economy with heterogeneity in preferences for the sin good and in the degree of time-inconsistency. They show that when there is some degree of self-control problems in the population such taxes not only counteract overconsumption by consumers with self-control problems, but can even create Pareto improvements.

A similar problem has been addressed by Aronsson and Thunström (2008), who consider the policy implications related to unhealthy food consumption in an economy with time-inconsistent individuals. Their result shows that a combination of subsidies for wealth and health capital makes the individual choose the same resource allocation as the social planner, thus internalizing the externality imposed by the individual's current self on her future selves.

Cremer et al. (2012) study the interaction between sin goods and health spending within two settings. In the first one, an individual is subject to persistent error and hence continues making biased choices. In the second one, an individual is modeled as a dual self, meaning that she later acknowledges the mistakes made by her previous biased self. Cremer et al. (2012) show that the first-best optimum can be decentralized by individualized taxes and subsidies. In the first setting, sin goods should be taxed and health-care expenditures subsidized. In the second, there is no need for subsidizing health-care expenditures, but a subsidy on saving is desirable.

Self-control problems related to smoking have been studied by Gruber and Köszegi (2001). These authors extend the model of Becker and Murphy (1988), where consumers

\footnotetext{
${ }^{3}$ See Business Roundtable (2007).
} 
are "rational addicts", by introducing time-inconsistent preferences. According to their results, individuals decrease their cigarette consumption already when future increases in tobacco taxes have been legislatively enacted but are not yet effective. This strongly refers to forward-looking behavior in consumption decisions. Moreover, the authors find that in the presence of time-inconsistency the optimal tax on cigarettes should not only depend on externalities, but also on the internal costs of smoking. Thus, excise taxes on cigarettes have a self-control function that is of high value to smokers who suffer from lack of commitment. In Gruber and Köszegi (2004), the authors introduce a self-control adjustment to standard tax incidence measures. This firstly lowers the overall incidence of tobacco taxes and secondly reduces their regressivity.

A systematic review from recent U.S. studies on the effectiveness of food and beverage taxes and subsides in improving public health was done by Powell et al. (2013). These studies analyze the relationship between prices/taxes on the demand for sugarsweetened beverages, fast-food, fruits and vegetables and on body weight outcomes. Soda taxes imposed on sugar-sweetened beverages, with mean price elasticity of -1.21 , do not seem to have much impact on weight. On the contrary, reducing prices for fruits and vegetables, with price elasticity of demand of about -0.5 , was found to be associated with lower weight outcomes. As the authors emphasize, this shows the effectiveness of subsidizing fruits and vegetables consumption. Hence, this review proves that relative price changes induced by taxes and subsidies have a significant impact on weight outcomes through consumption patterns.

However, not only governments, researchers and companies pay more attention to health outcomes and health-related interventions. Also the general public would support reducing health insurance taxes for individuals with healthy habits such as exercise and abstention from smoking, as shown by a cross-sectional telephone survey in Israel done by Brezis and Marans (2010). Support for a policy of differential taxation according to lifestyle was high across all sectors of society, even among smokers.

From all this we may conclude that, firstly, paternalistic instruments to promote long-term changes in an individual's behavior are welcomed by different social groups and, secondly, subsidies related to health-conscious behavior can improve health outcomes. By studying such subsidies, our paper adds to previous research which has put more emphasis on taxes. In particular, to the best of our knowledge, the timing of subsidies which is at the heart of our approach has not yet been analyzed.

We now turn to presenting the model which we use to address this issue. 


\section{The Model}

An individual consists of a sequence of autonomous temporal selves, which are indexed by the corresponding periods, $t=0,1,2, \ldots$. In each period $t$, a self with the exogenous and constant per-period income $y$ and the cash-on-hand $x_{t}$, which may differ from income because of taxes and subsidies, consumes a healthy good $c_{t}$ and a numeraire good $d_{t}$. We assume throughout that individuals cannot borrow or save. ${ }^{4}$ We will restrict our attention to steady state equilibria where choices and state variables are constant over time.

Normalizing current commodity prices to 1 , in the absence of government intervention, self $t$ 's budget constraint is given by $x_{t}=y=c_{t}+d_{t}$. Her instantaneous utility in period $t$ is

$$
u_{t} \equiv w\left(c_{t}\right)+v\left(d_{t}\right)+h_{t}
$$

where $w\left(c_{t}\right)$ and $v\left(d_{t}\right)$ denote a self's period- $t$ utility from consumption of healthy good and the numeraire, respectively. The function $h_{t}=h\left(c_{t-1}\right)$ represents the positive health consequences from past healthy good consumption, with $h_{0} \geq 0$ as the individual's initial (previous) health status. For this function, we use the normalization $h(0)=0$.

We assume that $v^{\prime}\left(d_{t}\right)>0, w^{\prime}\left(c_{t}\right)>0$ and $w^{\prime \prime}\left(c_{t}\right) \leq 0, v^{\prime \prime}\left(d_{t}\right) \leq 0$, so that there are positive and weakly decreasing marginal benefits of consumption. Similarly, consumption of the healthy good has positive but non-increasing marginal benefit for health, $h^{\prime}\left(c_{t-1}\right)>0$ and $h^{\prime \prime}\left(c_{t-1}\right) \leq 0$. To rule out corner solutions, we assume that at least one of the two second derivatives $w^{\prime \prime}$ or $v^{\prime \prime}$ is strictly negative. Moreover, we impose $w^{\prime}(0)+\delta h^{\prime}(0)>v^{\prime}(y)$ and $w^{\prime}(y)+\delta h^{\prime}(y)<v^{\prime}(0)$, where $\delta \in(0,1)$ represents timeconsistent discounting.

Following Laibson $(1994,1997)$ and O'Donoghue and Rabin $(1999)$, we adopt $(\beta, \delta)$ preferences in our model. A self's intertemporal preferences at time $t$ are thus given by

$$
U_{t}=u_{t}+\beta \sum_{i=1}^{\infty} \delta^{i} u_{t+i},
$$

where $\beta \in(0,1]$ measures the bias for the present. Within this preference structure we

\footnotetext{
${ }^{4}$ This paper does not aim at analyzing the interaction of savings with diverse paternalistic policies. Several papers have already demonstrated that hyperbolic consumers save less than exponential consumers (e.g. Laibson (1997, 1998), Angeletos et al. (2001), Diamond and Köszegi (2003)). This result is also expected in our framework.
} 
can distinguish two cases: for $\beta=1$, the preferences are time-consistent and reduced to exponential discounting, and for $\beta<1$, the preferences are present-biased and the discount rates decline over time.

Since a time-inconsistent individual consists of multiple selves, she is not able to commit to a particular future consumption behavior. Every self has a tendency to pursue immediate gratification in a way that their future selves do not appreciate. She will therefore choose a consumption level $\left(c_{t}, d_{t}\right)$ that maximizes her current utility $u_{t}$ plus a biased version of future utilities, as in (2), and not the individual's long-run utility as expressed by $U$ when $\beta=1$.

We begin our analysis by solving, as a reference case, the individual's optimization for $\beta=1$, where there is no need for government intervention. In this case, in each period $t$, a self with cash-on-hand $x_{t}$ chooses consumption $c_{t}$ and $d_{t}$. In the absence of taxes or subsidies, the first state variable $x_{t}$ is given exogenously and evolves according to the equation $x_{t+1}=y$. The second state variable $h_{t}$ is influenced by the past healthy good consumption and evolves according to the equation $h_{t+1}=h\left(c_{t}\right)$.

The unbiased choice is derived from the value function

$$
V\left(h_{t}, x_{t}\right)=\max _{c_{t}, d_{t}}\left\{w\left(c_{t}\right)+v\left(d_{t}\right)+h_{t}+\delta V\left(h_{t+1}, x_{t+1}\right) \mid x_{t}-c_{t}-d_{t}=0\right\}
$$

Denoting optimal choices as functions of cash-in-hand by $c\left(x_{t}\right)$ and $d\left(x_{t}\right)$, one finds after inserting $h_{t+1}=h\left(c_{t}\right)$ the first-order conditions

$$
w^{\prime}\left(c\left(x_{t}\right)\right)+\delta\left[\frac{\partial V\left(h_{t+1}, x_{t+1}\right)}{\partial h_{t+1}} \cdot h^{\prime}\left(c\left(x_{t}\right)\right)\right]=v^{\prime}\left(d\left(x_{t}\right)\right)=\lambda_{t}
$$

where $\lambda_{t}$ is the Lagrangian multiplier associated with the budget constraint. From the envelope theorem, one has $\partial V\left(h_{t+1}, x_{t+1}\right) / \partial h_{t+1}=1$. Using this in (4) shows that, for any time-constant exogenous per-period income $x_{t}=y$, the optimal solution of the above optimization problem $c^{*}=c^{*}(y)$ and $d^{*}=d^{*}(y)$ is stationary and given by the simultaneous solution to the budget constraint $c^{*}+d^{*}=y$ and

$$
w^{\prime}\left(c^{*}\right)+\delta h^{\prime}\left(c^{*}\right)=v^{\prime}\left(d^{*}\right) .
$$

Notice that from the assumptions on $w^{\prime \prime}, v^{\prime \prime}$ and $h^{\prime \prime}$ and the boundary assumptions on $w^{\prime}+\delta h^{\prime}$ and $v^{\prime}$, this solution is unique and satisfies $0<c^{*}(y), d^{*}(y)<y$. Intuitively, in the absence of present-biased preferences, marginal utilities of the numeraire and the 
healthy good are equalized, with the latter consisting of the immediate marginal benefit of consumption and of the delayed marginal impact on health.

\section{Corrective Policy}

We now consider the case where the individual has present-biased preferences. In the following Subsections 4.1 and 4.2, we analyze two measures to counterbalance the intertemporal distortion of consumption toward the present: an immediate subsidy related to health investment, and a future subsidy related to health outcome. Subsection 4.3 illustrates the results by means of two examples.

\subsection{Immediate subsidy}

Suppose that the government introduces a per unit subsidy $\tilde{z}_{t}$ on the individual's healthy good consumption $c_{t}$. To finance the subsidy payments, the government imposes a lump-sum tax $\tilde{\tau}_{t}$. Thus, cash-in-hand is $x_{t}=y-\tilde{\tau}_{t}$, and the price for the healthy commodity is reduced to $1-\tilde{z}_{t}$. The binding budget constraint is then given by $x_{t}=$ $\left(1-\tilde{z}_{t}\right) c_{t}+d_{t}$ or equivalently by $y=c_{t}+d_{t}+\tilde{\tau}_{t}-\tilde{z}_{t} c_{t}$. The state variable $x_{t}$ evolves according to the equation $x_{t+1}=y-\tilde{\tau}_{t+1}$. The state variable $h_{t}$ depends on the past healthy good consumption, so that it evolves according to $h_{t+1}=h\left(c_{t}\right)$. This is similar to the reference case, with the difference that consumption $c_{t}$ is now influenced by the subsidy $\tilde{z}_{t}$.

At time $t$, the current self $t$ uses the discount factor $\beta \delta$ and her current-value function can be written as

$$
W\left(h_{t}, x_{t}\right)=\max _{c_{t}, d_{t}}\left\{w\left(c_{t}\right)+v\left(d_{t}\right)+h_{t}+\beta \delta V\left(h_{t+1}, x_{t+1}\right) \mid x_{t}-\left(1-\tilde{z}_{t}\right) c_{t}-d_{t}=0\right\} .
$$

Denoting optimal choices again by $c\left(x_{t}\right)$ and $d\left(x_{t}\right)$, the first-order condition is

$$
\frac{w^{\prime}\left(c\left(x_{t}\right)\right)+\beta \delta\left[\frac{\partial V\left(h_{t+1}, x_{t+1}\right)}{\partial h_{t+1}} \cdot h^{\prime}\left(c\left(x_{t}\right)\right)\right]}{\left(1-\tilde{z}_{t}\right)}=v^{\prime}\left(d\left(x_{t}\right)\right) .
$$

Solving for $\tilde{z}_{t}$ yields

$$
\tilde{z}_{t}=1-\frac{w^{\prime}\left(c\left(x_{t}\right)\right)+\beta \delta\left[\frac{\partial V\left(h_{t+1}, x_{t+1}\right)}{\partial h_{t+1}} \cdot h^{\prime}\left(c\left(x_{t}\right)\right)\right]}{v^{\prime}\left(d\left(x_{t}\right)\right)} .
$$


Using $\partial V\left(h_{t+1}, x_{t+1}\right) / \partial h_{t+1}=1$, substituting $c^{*}=c^{*}(y)$ for $c\left(x_{t}\right)$ and $d^{*}=d^{*}(y)$ for $d\left(x_{t}\right)$ and rearranging, we get

$$
\tilde{z}_{t}=\tilde{z}=\frac{v^{\prime}\left(d^{*}\right)-w^{\prime}\left(c^{*}\right)-\beta \delta h^{\prime}\left(c^{*}\right)}{v^{\prime}\left(d^{*}\right)}
$$

With this subsidy rate, the unbiased choices satisfy the first-order condition (6) of every self $t$. When in addition, a lump sum tax is levied which covers subsidy payments, these choices also satisfy the budget constraint in every period.

Rewriting the subsidy rate $\tilde{z}$ with the help of (5), we summarize this result in the following proposition.

Proposition 1. The government can induce first-best consumption $c_{t}=c^{*}(y)$ and $d_{t}=d^{*}(y)$ in all periods $t=0,1,2, \ldots$ by granting an immediate subsidy

$$
\tilde{z}=\frac{\delta(1-\beta) h^{\prime}\left(c^{*}\right)}{v^{\prime}\left(d^{*}\right)}
$$

per unit of healthy consumption financed by lump-sum taxes $\tilde{\tau}_{t}=\tilde{\tau}=\tilde{z} c^{*}(y)$ in all periods $t=0,1,2, \ldots$.

For $\beta=1$, the numerator in (7) is zero so that there is no need for subsidizing health-conscious consumption. For $\beta<1$, the numerator gives the present value of the undervaluation of the marginal health benefit. The denominator is the marginal utility of income, so that the fraction $\tilde{z}$ describes by how much the marginal willingness to pay for the healthy good differs between the unbiased and the biased consumer. Thus, the optimal immediate subsidy $\tilde{z}$ balances the wedge between the biased and unbiased evaluation of health.

\subsection{Future subsidy}

Now we examine the second form of subsidies, namely, future subsidies rewarding good health outcomes. Suppose, therefore, that the government grants a subsidy $z_{t}$ on $h_{t}$ and imposes a lump-sum tax $\tau_{t}$ in order to finance the subsidy payments. Cash in hand is then given by $x_{t}=y-\tau_{t}+z_{t} h_{t}$, and the binding budget constraint is given by $x_{t}=c_{t}+d_{t}$ or $y=c_{t}+d_{t}+\tau_{t}-z_{t} h_{t}$. In the case of future subsidies the state variable $x_{t}$ evolves according to the equation of motion $x_{t+1}=y+z_{t+1} h_{t+1}-\tau_{t+1}$ and the state variable $h_{t}$ according to the equation $h_{t+1}=h\left(c_{t}\right)$. 
The maximization problem of the present self $t$ is given by the current-value function

$$
W\left(h_{t}, x_{t}\right)=\max _{c_{t}, d_{t}}\left\{w\left(c_{t}\right)+v\left(d_{t}\right)+h_{t}+\beta \delta V\left(h_{t+1}, x_{t+1}\right) \mid x_{t}-c_{t}-d_{t}=0\right\},
$$

where $V\left(h_{t+1}, x_{t+1}\right)$ is the continuation value function as in (3). The optimal choices solving this problem are again denoted by $c\left(x_{t}\right)$ and $d\left(x_{t}\right)$. In the Appendix it is shown that these functions satisfy the Euler equation

$$
\begin{array}{r}
v^{\prime}\left(d\left(x_{t}\right)\right)=w^{\prime}\left(c\left(x_{t}\right)\right)+\beta \delta h^{\prime}\left(c\left(x_{t}\right)\right)+\left\{v^{\prime}\left(d\left(x_{t+1}\right)\right)-(1-\beta)\left[w^{\prime}\left(c\left(x_{t+1}\right)\right) \cdot c^{\prime}\left(x_{t+1}\right)\right.\right. \\
\left.\left.+v^{\prime}\left(d\left(x_{t+1}\right)\right) \cdot d^{\prime}\left(x_{t+1}\right)\right]\right\} \delta z_{t+1} h^{\prime}\left(c\left(x_{t}\right)\right) .
\end{array}
$$

For given subsidy rate $z_{t+1}$, a solution to this equation consists of a choice function $c\left(x_{t}\right)$ and its derivative $c^{\prime}\left(x_{t+1}\right)$. From the budget constraint, these two values then determine $d\left(x_{t}\right)$ and $d^{\prime}\left(x_{t+1}\right)$. As there are still two free variables $c\left(x_{t}\right)$ and $c^{\prime}\left(x_{t+1}\right)$, there are multiple solutions to the Euler equation, even if one restricts attention to steady states. ${ }^{5}$ This arises since the decision of self $t$ depends on her expectation of self $t+1$ 's reaction to an increase in income $c^{\prime}\left(x_{t+1}\right)$. However, since this increase does not occur in equilibrium, the expectation is not determined in the model. ${ }^{6}$

In our analysis, we focus on a particularly appealing equilibrium, namely the one where the first-best choice function $c^{*}(y)$ and its derivative $c^{* \prime}(y)$ solve the Euler equation in every period, that is $c\left(x_{t}\right)=c^{*}(y)$ and $c^{\prime}\left(x_{t+1}\right)=c^{* \prime}(y)$ for all $t=0,1,2, \ldots$ To find the subsidy rate which achieves this, solving (9) for $z_{t+1}$ yields

$$
z_{t+1}=\frac{v^{\prime}\left(d\left(x_{t}\right)\right)-w^{\prime}\left(c\left(x_{t}\right)\right)-\beta \delta h^{\prime}\left(c\left(x_{t}\right)\right)}{\delta h^{\prime}\left(c\left(x_{t}\right)\right)\left\{v^{\prime}\left(d\left(x_{t+1}\right)\right)-(1-\beta)\left[w^{\prime}\left(c\left(x_{t+1}\right)\right) \cdot c^{\prime}\left(x_{t+1}\right)+v^{\prime}\left(d\left(x_{t+1}\right)\right) \cdot d^{\prime}\left(x_{t+1}\right)\right]\right\}} .
$$

By substitution of $c^{*}=c^{*}(y), d^{*}=d^{*}(y), c^{* \prime}(y)$, and $d^{* \prime}(y)$ from the stationary firstbest solution given in (5), and observing that $x_{t+1}=y$ if the government runs a balanced budget, we arrive at the following result:

Proposition 2. If the government subsidizes health outcome in periods $t=1,2, \ldots$ at the rate

$$
z=\frac{(1-\beta)}{v^{\prime}\left(d^{*}\right)-(1-\beta)\left[w^{\prime}\left(c^{*}\right) c^{* \prime}(y)+v^{\prime}\left(d^{*}\right) d^{*^{\prime}}(y)\right]}
$$

\footnotetext{
${ }^{5}$ This is a common feature of models with quasi-hyperbolic discounting and infinite time horizon. See e.g. Karp (2005), p. 269-271.

${ }^{6}$ In contrast, when the subsidy is paid immediately as in Proposition 1, self $t$ 's choice does not affect self $t+1$ 's behavior, and hence her behavior is uniquely determined.
} 
and imposes taxes $\tau_{0}=0$ and $\tau_{t}=\tau=z h\left(c^{*}\right)$ in all subsequent periods $t=1,2, \ldots$, the first-best behavior $c_{t}=c^{*}(y), d_{t}=d^{*}(y)$ in all $t=0,1,2, \ldots$ is an equilibrium despite present-biased preferences.

To interpret the rate $z$ in (10), note first that for $\beta=1$ the numerator is zero and there is no need for subsidizing health-conscious consumption. For $\beta<1$, we multiply the numerator and the denominator on the right-hand-side of (10) by $\delta h^{\prime}\left(c^{*}\right)$ and rearrange to obtain

$$
z \delta h^{\prime}\left(c^{*}\right)\left\{v^{\prime}\left(d^{*}\right)-(1-\beta)\left[w^{\prime}\left(c^{*}\right) c^{* \prime}(y)+v^{\prime}\left(d^{*}\right) d^{* \prime}(y)\right]\right\}=\delta(1-\beta) h^{\prime}\left(c^{*}\right) .
$$

The right-hand-side of (11) equals, as in (7), the marginal benefit of healthy consumption which self $t$ does not take into account because of her present bias. Considering the left-hand-side of (11), we observe first that increasing healthy consumption by one unit in period $t$ increases the subsidy in period $t+1$ by $z h^{\prime}\left(c^{*}\right)$ units. Moreover, the curly bracket is $\beta \partial V\left(h_{t+1}, x_{t+1}\right) / \partial x_{t+1}$, evaluated at first-best values. ${ }^{7}$ Multiplied by $\delta$, this is the utility gain accruing to self $t$ if the income of self $t+1$ is raised by one unit. Altogether, the left-hand-side of (11) describes the additional utility that self $t$ acquires through the subsidy if she increases healthy consumption by one unit. The optimal rate $z$ is set such that this subsidy-induced utility gain equals the bias in the evaluation of future health benefit, thereby correcting for the bias.

Comparing (10) to the optimal subsidy rate in case of immediate subsidization in (7), one first notices the discount factor $\delta$ and the marginal health impact of consumption $h^{\prime}\left(c^{*}\right)$ in the numerator of $(7)$. These differences reflect the facts that the immediate subsidy is paid one period earlier and based on consumption of the healthy good rather than on health outcome. Moreover, both forms of subsidy differ because of two other, less obvious, effects which are generated by present-biased behavior.

The first effect, which we label as discounting effect, arises because self $t$, who takes the decision on healthy consumption, evaluates period $t+1$ income differently from self $t+1$, who receives the subsidy. Since for self $t$, this additional income accrues in the future, she disregards the fraction $1-\beta$ of the benefits procured by marginal spending on both goods. Formally, this is expressed by the fact that in the denominator of (10) the term $(1-\beta)\left[w^{\prime}\left(c^{*}\right) \cdot c^{* \prime}(y)+v^{\prime}\left(d^{*}\right) \cdot d^{* \prime}(y)\right]$ is subtracted from the marginal utility of income. This effect raises the optimal future subsidy rate $z$ compared to the optimal

\footnotetext{
${ }^{7}$ See equation (A.5) in the Appendix.
} 
current rate $\tilde{z}$.

The second effect, which we label as instrumental effect, occurs since the future subsidy allows self $t$ to shift self $t+1$ 's spending in a way self $t$ appreciates. From self $t$ 's perspective, there should be no additional discounting of health benefit from period $t+2$ to period $t+1$. Since self $t+1$ takes her decision subject to such a bias, the current self anticipates that the future self spends less on healthy consumption than what the current self considers optimal.

To see that the future subsidy provides an instrument for self $t$ to correct this bias, use (5) in the denominator of (10) and observe that $c^{* \prime}(y)+d^{* \prime}(y)=1$. The optimal future subsidy rate can then be written as

$$
z=\frac{1-\beta}{\beta v^{\prime}\left(d^{*}\right)+(1-\beta) \delta h^{\prime}\left(c^{*}\right) c^{* \prime}(y)} .
$$

If the marginal propensity to consume the healthy good $c^{* \prime}(y)$ is zero, then the denominator of (12) reduces to $\beta v^{\prime}\left(d^{*}\right)$, self $t$ 's evaluation of self $t+1$ 's marginal utility of income. However, when some of the additional income is spent on the healthy good $\left(c^{* \prime}(y)>0\right)$, self $t$ values an additional unit of subsidy higher than $\beta v^{\prime}\left(d^{*}\right)$. From self $t$ 's perspective, the health benefit in period $t+2$ is undervalued by self $t+1$, and hence self $t$ welcomes any additional spending on the healthy good. Consequently, the optimal subsidy rate decreases in the marginal propensity to consume the healthy good $c^{* \prime}(y)$. Compared to the immediate rate $\tilde{z}$, this effect tends to reduce the optimal future subsidy rate $z$.

The importance of the income effect is illustrated by means of two special cases, to which we now turn.

\subsection{Special cases}

The cases we consider are characterized by quasi-linear preferences regarding consumption goods $c$ and $d$ respectively. To focus on the shape of utility functions $w$ and $v$, we assume that $h(c)=c$ in both cases.

In the first special case, the numeraire enters utility linearly, so that $v(d)=d$, whereas the healthy good has decreasing marginal utility, $w^{\prime \prime}(c)<0$. Then $c^{* \prime}(y)=0$ and $d^{* \prime}(y)=1$, and the optimal subsidy rates from (7) and (10) are $\tilde{z}=\delta(1-\beta)$ and $z=(1-\beta) / \beta$, implying $\tilde{z}=\delta \beta z$. As explained above, the optimal future subsidy rate reflects both the current self's biased valuation of future income (the discounting effect) 
and her benefit from changing the future self's behavior (the instrumental effect). In this special case, where no part of additional income is spent on the healthy good, only the discounting effect is present. Therefore, the ratio of the current to the future subsidy rate simply reflects the current self's discounting of future income.

The second special case is given by a utility function where the healthy good enters linearly, while numeraire $d$ has decreasing marginal utility, $v^{\prime \prime}(d)<0$. In order to make both cases comparable, we again fix the total marginal utility of the linear good to unity, implying, with $h(c)=c$, that $w(c)=(1-\delta) c$. Then $c^{* \prime}(y)=1$ and $d^{* \prime}(y)=0$ and the optimal subsidy rates from (7) and (10) are $\tilde{z}=\delta(1-\beta)$ and $z=(1-\beta) /[\beta+\delta(1-\beta)]$, yielding $\tilde{z}=z\left[\delta \beta+\delta^{2}(1-\beta)\right]$. Hence, in this case, the ratio of current to future subsidy rate is larger.

To explain this, we first observe that the immediate subsidy rates are the same regardless of whether the preferences are linear in the healthy good or in the numeraire. Considering future subsidy rates, one notices that the term $\delta(1-\beta)$, which describes the disregarded health effect in the future, appears only in the case when the healthy good enters utility linearly. In this case, the additional income procured by the future subsidy will be entirely used for consumption of the healthy good. Hence, the instrumental effect is maximal in this case. Therefore, the subsidy appears more useful to self $t$ than in the general case when both goods are normal, and even more useful compared to the first special case where no such correction is achieved. As a consequence, a smaller future subsidy rate is sufficient to induce unbiased behavior.

\section{Tax Revenues}

We now compare the tax revenue necessary to induce first-best behavior by immediate subsidies on consumption of the healthy good with the taxes required to reach the same goal by future subsidies on the health outcome. Using $\tilde{z}$ and $z$ from (7) and (10), the present values of immediate $(\tilde{T})$ and future $(T)$ subsidies are

$$
\begin{aligned}
\tilde{T} & =\sum_{t=0}^{\infty} \delta^{t} \tilde{z} c^{*}=\frac{\tilde{z} c^{*}}{1-\delta}, \\
T & =\sum_{t=1}^{\infty} \delta^{t} z h\left(c^{*}\right)=\frac{\delta z h\left(c^{*}\right)}{1-\delta}
\end{aligned}
$$


This comparison is motivated by the fact that in general, taxes induce some welfare loss. Instead of modeling such costs explicitly, we simply assume that the government prefers the form of subsidization that results in lower present value of taxes. That is, formally, the government has lexicographic preferences over the allocation $(c, d)$ and tax revenues.

Alternatively, one can easily introduce a simple type of excess burden consisting of a product of two factors: exogenous marginal costs of public funds $(\alpha)$ and tax revenue. Integrating this excess burden, per period utility from (1) is modified to

$$
u_{t}=w\left(c_{t}\right)+v\left(d_{t}\right)+h_{t}-\alpha \tau_{t} .
$$

Using this formulation, one obtains the government's evaluation of the intertemporal utility which the individual achieves when an immediate subsidy according to Proposition 1 is paid:

$$
\tilde{U}=h_{0}+\frac{1}{1-\delta}\left[w\left(c^{*}\right)+v\left(d^{*}\right)+\delta h\left(c^{*}\right)\right]-\alpha \tilde{T} .
$$

In the same way we compute the intertemporal utility with future subsidy according to Proposition 2:

$$
U=h_{0}+\frac{1}{1-\delta}\left[w\left(c^{*}\right)+v\left(d^{*}\right)+\delta h\left(c^{*}\right)\right]-\alpha T .
$$

Clearly, in both cases utility is decreasing in the present value of tax payments. Therefore, it is worthwhile to ask which of the two subsidy schemes induces the first-best consumption at lower cost to the government. ${ }^{8}$

The following proposition answers this question.

Proposition 3. If $\beta<1$, inducing unbiased choices by immediately subsidizing healthy consumption requires a lower present value of taxes than inducing unbiased choices by subsidizing the future health outcome, $\tilde{T}<T$.

Proof: Inserting (7) and (12) in (13) and (14) shows that $\tilde{T}<T$ is equivalent to

$$
\frac{\delta}{1-\delta} \cdot \frac{(1-\beta) h^{\prime}\left(c^{*}\right) c^{*}}{v^{\prime}\left(d^{*}\right)}<\frac{\delta}{1-\delta} \cdot \frac{(1-\beta) h\left(c^{*}\right)}{\beta v^{\prime}\left(d^{*}\right)+(1-\beta) \delta h^{\prime}\left(c^{*}\right) c^{* \prime}(y)}
$$

\footnotetext{
${ }^{8}$ In a more elaborate set-up, one might account for the excess burden when determining the optimal policy. This will probably result in lower subsidy rates, since there is then a trade-off between the welfare cost of taxation and the health-improvement. However, this trade-off is not the subject of this paper, where we instead focus on costs of corrective policies which implement the first-best choice.
} 
For $\beta<1$, this inequality is equivalent to

$$
h^{\prime}\left(c^{*}\right) c^{*} \cdot\left[\beta v^{\prime}\left(d^{*}\right)+(1-\beta) \delta h^{\prime}\left(c^{*}\right) c^{* \prime}(y)\right]<v^{\prime}\left(d^{*}\right) h\left(c^{*}\right) .
$$

Now observe that $c^{* \prime}(y)=v^{\prime \prime} /\left(w^{\prime \prime}+\delta h^{\prime \prime}+v^{\prime \prime}\right) \leq 1$ and that the concavity of $h\left(c^{*}\right)$ implies with $h(0)=0$ that $h^{\prime}\left(c^{*}\right) c^{*} \leq h\left(c^{*}\right)$. Therefore, one has

$$
h^{\prime}\left(c^{*}\right) c^{*} \cdot\left[\beta v^{\prime}\left(d^{*}\right)+(1-\beta) \delta h^{\prime}\left(c^{*}\right) c^{* \prime}(y)\right] \leq h\left(c^{*}\right) \cdot\left[\beta v^{\prime}\left(d^{*}\right)+(1-\beta) \delta h^{\prime}\left(c^{*}\right)\right] .
$$

With (5), this inequality is equivalent to

$$
h^{\prime}\left(c^{*}\right) c^{*} \cdot\left[\beta v^{\prime}\left(d^{*}\right)+(1-\beta) \delta h^{\prime}\left(c^{*}\right) c^{* \prime}(y)\right] \leq h\left(c^{*}\right) \cdot\left[v^{\prime}\left(d^{*}\right)-(1-\beta) w^{\prime}\left(c^{*}\right)\right] .
$$

For $\beta<1$, this inequality implies (15) and hence $\tilde{T}<T$. Q.E.D.

This result shows that the future subsidy is more expensive in terms of tax revenues required than the immediate subsidy. Politically this means that those subsidy instruments which reward health-conscious behavior such as immediate financial rewards are preferable to instruments which reward health outcomes such as health insurance rebates.

Proposition 3 is a consequence of the various effects determining the optimal subsidy rates explained after Proposition 2. The dominating force is the discounting effect, that is the difference in discounting between the individual decision maker and the government. The future subsidy achieves the same behavioral response as the present subsidy only if it is sufficiently high to compensate for the current self's present bias. The government, in contrast, is unbiased in its intertemporal evaluation of tax revenues. This is most clearly seen in the special case where the numeraire enters utility in a linear fashion. In this case, to achieve the first-best, the future subsidy rate must be $1 / \beta \delta$ times higher than the immediate subsidy rate. When calculating the present values, the government discounts the future subsidy only with $\delta$. Therefore, the present value of the future subsidy still exceeds the present value of the immediate subsidy by the factor $1 / \beta$.

In general, however, this result is mitigated by the instrumental effect. As discussed after Proposition 2, the future subsidy allows self $t$ to counteract the present bias of self $t+1$. Since this makes the future subsidy more valuable for self $t$, a smaller subsidy rate is sufficient to achieve first-best consumption. Consequently, the present value of the future subsidy is reduced to some extent. As Proposition 3 shows, however, the 
discounting effect dominates the instrumental effect, so that the immediate subsidy still involves lower taxes.

\section{Present-biased Policymaker}

In this section we take a different perspective on the political decision making process. Until now we considered a paternalistic government with time-consistent preferences which induces the individual to behave as if there was no present bias. In the following we assume that the present-biased individual herself forms the government. This means that the government on the one hand, like the individual, discounts more heavily between the current and the following periods than between later periods. On the other hand, like the paternalistic government, it can impose taxes and pay subsidies. In this scenario two questions arise: Will the present-biased policymaker commit to a subsidy scheme which implements the first-best choice? If so, which form of the subsidy will she prefer?

\subsection{Commitment}

To address the first issue, we compare the intertemporal utility that the present-biased government obtains with the first-best allocation to the utility it would achieve without any intervention. ${ }^{9}$ This laissez-faire allocation is given by the solution to the hyperbolic self's decision problem analyzed in Subsection 4.1 with $\tilde{z}_{t}=\tilde{\tau}_{t}=0$. From the first-order condition (6), using $\partial V\left(h_{t+1}, x_{t+1}\right) / \partial h_{t+1}=1$, a stationary solution $\left(c_{\beta}, d_{\beta}\right)$ satisfies $w^{\prime}\left(c_{\beta}\right)+\beta \delta h^{\prime}\left(c_{\beta}\right)=v^{\prime}\left(d_{\beta}\right)$ and the budget constraint $c_{\beta}+d_{\beta}=y$. In this solution, healthy consumption is lower and numeraire consumption is larger than in the firstbest, $c_{\beta}<c^{*}, d_{\beta}>d^{*}$.

The present-biased policymaker will commit to a subsidy scheme if the intertemporal utility $U^{*}$ provided by first-best consumption $\left(c^{*}, d^{*}\right)$ exceeds the intertemporal utility $U_{\beta}$ provided by $\left(c_{\beta}, d_{\beta}\right)$. Inserting $c^{*}$ and $d^{*}$ or, respectively, $c_{\beta}$ and $d_{\beta}$ in (1) and using

\footnotetext{
${ }^{9}$ In a more general approach one could allow the present-biased government to choose an allocation which is different from these two. While it would be easy to characterize such an allocation, we restrict attention to the choice between first-best and laissez-faire. By keeping the subsidy rates and the resulting allocation unchanged, we focus on the choice of timing of the subsidy, thus maintaining comparability with the previous analysis.
} 
(2) yields

$$
\begin{aligned}
& U^{*}=h_{0}+w\left(c^{*}\right)+v\left(d^{*}\right)+\beta \delta h\left(c^{*}\right)+\beta \sum_{t=1}^{\infty} \delta^{t}\left[w\left(c^{*}\right)+\delta h\left(c^{*}\right)+v\left(d^{*}\right)\right] \\
& U_{\beta}=h_{0}+w\left(c_{\beta}\right)+v\left(d_{\beta}\right)+\beta \delta h\left(c_{\beta}\right)+\beta \sum_{t=1}^{\infty} \delta^{t}\left[w\left(c_{\beta}\right)+\delta h\left(c_{\beta}\right)+v\left(d_{\beta}\right)\right]
\end{aligned}
$$

Inspecting these two expressions one notices the trade-off faced by the present-biased policymaker in period 0. By implementing the subsidy as of period 0, she induces her own consumption to change to the first-best values which, due to her present-bias, she deems inferior to the laissez-faire values. Hence, she loses

$$
\Delta_{\beta}=w\left(c_{\beta}\right)+v\left(y-c_{\beta}\right)+\beta \delta h\left(c_{\beta}\right)-\left[w\left(c^{*}\right)+v\left(y-c^{*}\right)+\beta \delta h\left(c^{*}\right)\right]>0
$$

in period 0 . In return she gains

$$
\Delta^{*}=w\left(c^{*}\right)+v\left(y-c^{*}\right)+\delta h\left(c^{*}\right)-\left[w\left(c_{\beta}\right)+v\left(y-c_{\beta}\right)+\delta h\left(c_{\beta}\right)\right]>0
$$

in every period $t=1,2, \ldots$. This gain arises since self $t=0$ likes the consumption of future selves $t=1,2, \ldots$ to be changed to the first-best values. Calculating present values, one finds

$$
U^{*}-U_{\beta}=-\Delta_{\beta}+\frac{\beta \delta}{1-\delta} \Delta^{*}
$$

The present-biased policymaker chooses to implement the subsidy if this expression is non-negative.

Figure 1 illustrates the loss $\Delta_{\beta}$ and the gain $\Delta^{*}$. For self 0 , the marginal benefit of her own healthy consumption is reduced by present-bias, as shown by the line labeled $w^{\prime}(c)+\beta \delta h^{\prime}(c)$ in Figure 1. For consumption levels between $c_{\beta}$ and $c^{*}$, this marginal benefit falls short of the marginal benefit of the numeraire, expressed by the line labeled $v^{\prime}(y-c)$ in Figure 1 . The resulting loss $\Delta_{\beta}$ is depicted by the vertically shaded area between these two curves. In contrast, self 0 evaluates the marginal benefit of healthy consumption by future selves $t=1,2, \ldots$ without a present-bias. This marginal benefit is given by the line labeled $w^{\prime}(c)+\delta h^{\prime}(c)$ in Figure 1. It exceeds the marginal utility of the numeraire for consumption levels between $c_{\beta}$ and $c^{*}$. The gain $\Delta^{*}$ is then represented by the horizontally shaded area between the $w^{\prime}(c)+\delta h^{\prime}(c)$ and $v^{\prime}(y-c)$ curves.

Clearly, the sign of $U^{*}-U_{\beta}$ in (16) depends on the exact sizes of these areas, and 


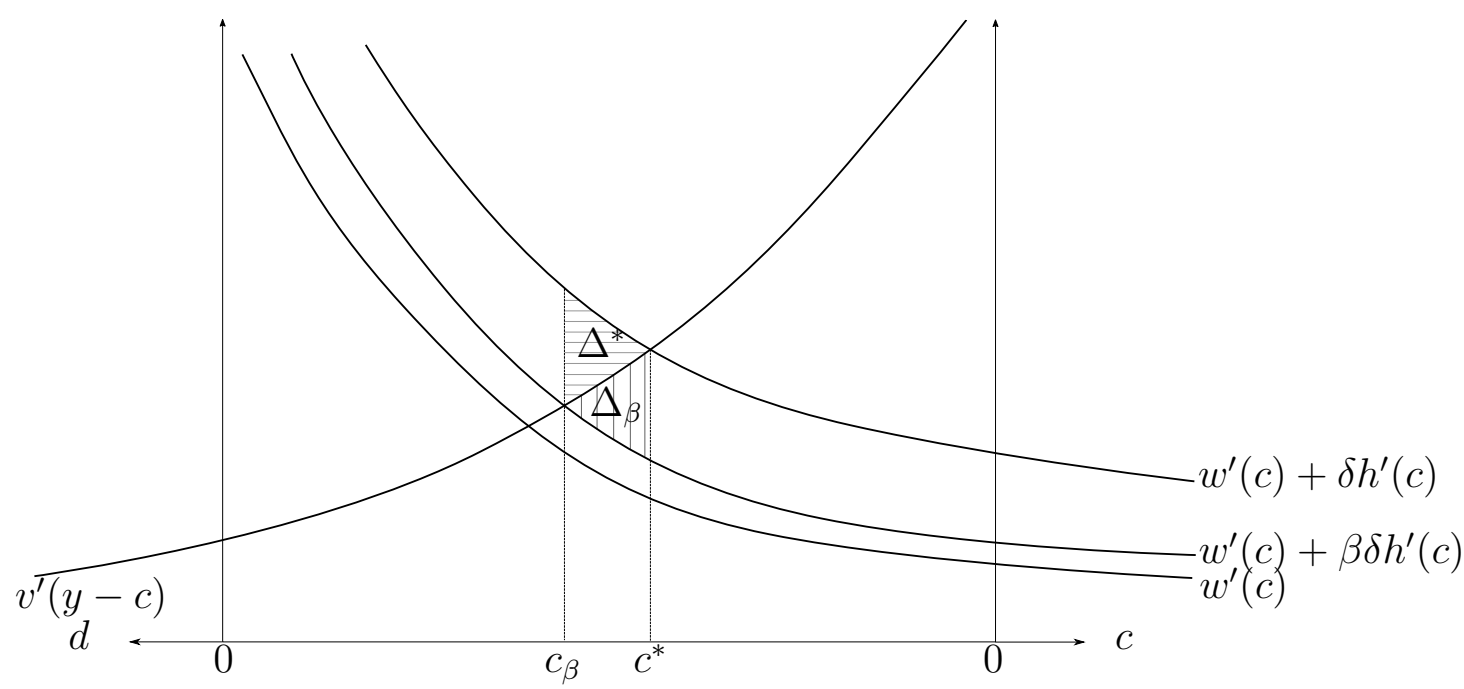

Figure 1: Gain $\left(\Delta^{*}\right)$ and loss $\left(\Delta_{\beta}\right)$ procured to the present-biased policymaker when committing to a subsidy scheme.

hence on the shape of the marginal utility schedules involved. However, if these do not display too strong curvatures, the decision on the subsidy scheme is essentially determined by the discount rates, as the following proposition shows.

Proposition 4. Assume that $w^{\prime \prime \prime}=v^{\prime \prime \prime}=h^{\prime \prime \prime}=0$. Then the present-biased policymaker will commit to one of the subsidy schemes described in Propositions 1 and 2 if and only if

$$
\frac{\beta \delta}{1-\delta} \geq \frac{h^{\prime}\left(c^{*}\right)}{h^{\prime}\left(c_{\beta}\right)}
$$

Proof: $\quad$ With $w^{\prime \prime \prime}=v^{\prime \prime \prime}=h^{\prime \prime \prime}=0$, the marginal cost curves $w+\beta \delta h^{\prime}, w+\delta h^{\prime}$, and $v^{\prime}$ are linear. Hence, $\Delta^{*}=\left(c^{*}-c_{\beta}\right)(1-\beta) \delta h^{\prime}\left(c_{\beta}\right) / 2$ and $\Delta_{\beta}=\left(c^{*}-c_{\beta}\right)(1-\beta) \delta h^{\prime}\left(c^{*}\right) / 2$ (see Figure 1). Inserting in (16) shows that $U^{*}-U_{\beta} \geq 0$ is equivalent to (17). Q.E.D.

Note that this result can easily be extended to the case where marginal utilities are not exactly linear, as long as their curvatures are not too strong. Thus, the presentbiased policymaker will still choose to implement (not to implement) the first-best consumption levels if $\beta /(1-\beta)>(<) h^{\prime}\left(c^{*}\right) / h^{\prime}\left(c_{\beta}\right)$ as long as the third derivatives of the utility functions are not too large.

Moreover, we note that this choice is time-consistent. Since the policymaker in period 1 is in the same situation as the policymaker in period 0 , she will commit to the subsidy if and only if the policymaker in period 0 commits to it. Therefore, she will not abolish the subsidy once it is introduced. Conversely, it would not be time-consistent if 
the policymaker in period 0 decided to implement the subsidy scheme only from period 1 onward. While this is the best choice for this policymaker, the subsequent government would behave in the same way and hence postpone the starting date for the subsidy scheme by one more period, and so on.

Proposition 4 shows that a government which is formed by the individuals sometimes fails to implement the first-best policy. This occurs if the future gains from committing to increased healthy consumption count too little compared to the immediate loss from forcing a change of behavior upon oneself. On the other hand, if discounting is not too strong, that is, if inequality (17) is satisfied, one does not have to appeal to an outside paternalistic government in order to induce first-best.

\subsection{Tax revenues}

We now turn to the choice between immediate and future subsidies. We assume that the present-biased government, like the paternalistic government, prefers the form of subsidies that requires the lower present value of taxes. However, the present values of immediate $\left(\widetilde{T}_{\beta}\right)$ and future $\left(T_{\beta}\right)$ subsidies are calculated taking into account the policymaker's present-bias:

$$
\begin{aligned}
& \widetilde{T}_{\beta}=\delta^{0} \widetilde{z} c^{*}+\beta \sum_{t=1}^{\infty} \delta^{t} \widetilde{z} c^{*}=\frac{[1-\delta(1-\beta)] \widetilde{z} c^{*}}{1-\delta} \\
& T_{\beta}=\beta \sum_{t=1}^{\infty} \delta^{t} z h\left(c^{*}\right)=\frac{\beta \delta z h\left(c^{*}\right)}{1-\delta}
\end{aligned}
$$

The following proposition shows that the evaluation of tax revenues by the policymaker now depends on the extent of her bias towards the present.

Proposition 5. There is a critical $\hat{\beta}$ with $0 \leq \hat{\beta} \leq 1$ such that, for all $0<\beta<1$

$$
T_{\beta}\{\lesseqgtr\} \widetilde{T}_{\beta} \text { if and only if } \beta\{\lesseqgtr\} \hat{\beta} \text {. }
$$

Proof: See the Appendix.

In contrast to Proposition 5 the comparison of tax revenues by the present-biased policymaker does not always favor the immediate subsidy scheme. This can be understood by considering how the different computation of present values by the paternalistic and the present-biased government interacts with the effects determining optimal subsidy rates. The present-biased government discounts future tax payments more heavily, 
therefore in its computation the discounting effect raises the cost of future subsidies less than in the computation of the paternalistic government. As a consequence it is possible that the instrumental effect dominates.

This can be illustrated by considering the two special cases presented in Subsection 4.3. In the first special case, where $c^{* \prime}(y)=0$, the instrumental effect is absent. As shown in the proof of Proposition 5 , in this case $\hat{\beta}=0$ implying that the future subsidy is always more expensive that the immediate subsidy. Thus in this case both types of government evaluate tax revenues in the same way.

In the second special case, where $c^{* \prime}(y)=1$, the instrumental effect is strongest. In this case $T_{\beta}<\tilde{T}_{\beta}$ for all $0<\beta<1,{ }^{10}$ or equivalently $\hat{\beta}=1$. Thus the strong instrumental effect outweighs the discounting effect, so that the future subsidy is always less expensive compared to the immediate subsidy.

Finally, we note that this example shows that there are parameter constellations such that in the same time inequality (17) holds and $T_{\beta}<\tilde{T}_{\beta}$. Thus, even if the present-biased policymaker agrees with the paternalistic government that the first-best allocation is preferable to laissez-faire, she may choose a different form of subsidy.

\section{Conclusion}

This paper analyzes the intrapersonal game that arises when a consumer with presentbiased preferences faces an intertemporal consumption decision. In this setting, we examine two forms of subsidizing health conscious behavior: immediate subsidies related to healthy consumption and future subsidies paid for a good health outcome. We show that while both subsidies can achieve the first-best outcome, it then very much depends on the policymaker's preferences which one of the subsidy schemes will be implemented.

This choice is driven by the balance of two effects determining the effectiveness of the future subsidy. On the one hand, present-biased consumers perceive future subsidy payments as less valuable, and hence, the effectiveness of rewards for health-conscious behavior declines the further they are in the future. On the other hand, procuring later selves with additional income raises future health-conscious consumption via an income effect, which makes future subsidies more effective. Our first result shows that, for a paternalistic government, the first effect always dominates so that the future subsidy

\footnotetext{
${ }^{10}$ To see this, insert $v^{\prime}\left(d^{*}\right)=h^{\prime}\left(c^{*}\right)=\varepsilon=1$ in equation (A.7) in the Appendix.
} 
results in higher costs measured in present value terms. Politically, this implies that the paternalistic government should concentrate on rewarding health-conscious behavior, e.g. by lowering the prices of healthy goods, rather than promising future rewards for successful health investments.

We contrast this result with the decision taken by a present-biased government which is formed by time-inconsistent individuals. We show that such a government will commit to a subsidy scheme which implements the unbiased choice when future gains from commitment to increased healthy consumption exceed the immediate loss from forcing a behavior change. However, in contrast to the first result, the comparison of tax revenues by the biased government does not always favor the immediate subsidy scheme. Since the present-biased government uses a stronger discount factor, the cost of future subsidies count for relatively less. If the income effect on future behavior is strong enough, the present-biased government will therefore favor the future subsidy scheme.

Our results suggest a number of extensions, two of which we briefly discuss. The first extension concerns the effectiveness of subsidies, which may not only depend on the timing, but also on the type of reward. As the examples given in the introduction illustrate, premia for health-related activities are often awarded in kind. This matters since we could imagine that for present-biased consumers money is a more attractive immediate reward than, say, a free fitness card. In the same time, money can be spent on many things including consumption which damages health, whereas a fitness card procures an additional health benefit. Hence, it might be interesting to find out the optimal combination of monetary and in-kind subsidies for health.

As a second extension, one can ask the general question of whether or not the intervening government can be assumed to have time-consistent preferences. If, as in our model, all individuals have to some extent present-biased preferences, who will form the unbiased government? Alternatively, if there is a minority of unbiased individuals, can we expect them to be elected by the biased majority? Conversely, when the government is composed of biased individuals, how likely is that it will implement a policy that actually goes against the current preferences of its members? And if so, will it be able to put an end to its own postponing game? Finally, do the paternalistic or presentbiased governments have to give a reason for their action?

In our view, a convincing theory of policy intervention for correcting biased preferences should address such political economy issues. These considerations are, however, beyond the scope of this paper and will be the subject of further research. 


\section{Appendix}

\section{Derivation of the Euler equation}

Computing the first-order conditions for a solution to (8) and using $\partial h_{t+1} / \partial c_{t}=h^{\prime}\left(c_{t}\right)$ and $\partial x_{t+1} / \partial c_{t}=z_{t+1} h^{\prime}\left(c_{t}\right)$, we obtain

$$
\lambda_{t}=w^{\prime}\left(c\left(x_{t}\right)\right)+\beta \delta\left(\frac{\partial V\left(h_{t+1}, x_{t+1}\right)}{\partial h_{t+1}}+\frac{\partial V\left(h_{t+1}, x_{t+1}\right)}{\partial x_{t+1}} \cdot z_{t+1}\right) \cdot h^{\prime}\left(c\left(x_{t}\right)\right)=v^{\prime}\left(d\left(x_{t}\right)\right)
$$

where $\lambda_{t}$ is the Lagrange variable associated to the budget constraint. Inserting optimal choices in the current-value function for the present-biased consumer gives

$$
W\left(h_{t}, x_{t}\right)=w\left(c\left(x_{t}\right)\right)+v\left(d\left(x_{t}\right)\right)+h_{t}+\beta \delta V\left(h_{t+1}, x_{t+1}\right)
$$

Using the laws of motion for $x_{t+1}$ and $h_{t+1}$, one derives from (A.2)

$$
\begin{gathered}
\frac{\partial W\left(h_{t}, x_{t}\right)}{\partial x_{t}}=\left[w^{\prime}\left(c\left(x_{t}\right)\right)+\beta \delta\left(\frac{\partial V\left(h_{t+1}, x_{t+1}\right)}{\partial h_{t+1}}+\frac{\partial V\left(h_{t+1}, x_{t+1}\right)}{x_{t+1}} \cdot z_{t+1}\right) \cdot h^{\prime}\left(c\left(x_{t}\right)\right)\right] \cdot c^{\prime}\left(x_{t}\right) \\
+v^{\prime}\left(d\left(x_{t}\right)\right) \cdot d^{\prime}\left(x_{t}\right), \\
\frac{\partial W\left(h_{t}, x_{t}\right)}{\partial h_{t}}=1 .
\end{gathered}
$$

From the envelope theorem, we have

$$
\frac{\partial W\left(h_{t}, x_{t}\right)}{\partial x_{t}}=\lambda_{t}=v^{\prime}\left(d\left(x_{t}\right)\right)
$$

Substituting next period's optimal choices $c\left(x_{t+1}\right)$ and $d\left(x_{t+1}\right)$ into the continuationvalue function yields

$$
V\left(h_{t+1}, x_{t+1}\right)=w\left(c\left(x_{t+1}\right)\right)+v\left(d\left(x_{t+1}\right)\right)+h_{t+1}+\delta V\left(h_{t+2}, x_{t+2}\right) .
$$

From (A.4) and the equivalent of (A.2) for period $t+1$, the current-value function and the continuation-value function are linked by the equation ${ }^{11}$

$$
\beta \cdot V\left(h_{t+1}, x_{t+1}\right)=W\left(h_{t+1}, x_{t+1}\right)-(1-\beta)\left[w\left(c\left(x_{t+1}\right)\right)+v\left(d\left(x_{t+1}\right)\right)+h_{t+1}\right]
$$

\footnotetext{
${ }^{11}$ See also Harris and Laibson (2001), p. 940.
} 
By differentiation and substitution of the version of (A.3) for period $t+1$ we get

$\beta \cdot \frac{\partial V\left(h_{t+1}, x_{t+1}\right)}{\partial x_{t+1}}=v^{\prime}\left(d\left(x_{t+1}\right)\right)-(1-\beta)\left[w^{\prime}\left(c\left(x_{t+1}\right)\right) \cdot c^{\prime}\left(x_{t+1}\right)+v^{\prime}\left(d\left(x_{t+1}\right)\right) \cdot d^{\prime}\left(x_{t+1}\right)\right]$

with $w^{\prime}\left(c\left(x_{t+1}\right)\right) \cdot c^{\prime}\left(x_{t+1}\right)+v^{\prime}\left(d\left(x_{t+1}\right)\right) \cdot d^{\prime}\left(x_{t+1}\right)$ as the current marginal utility of income. From the equation (A.1) we have

$$
\beta \cdot \frac{\partial V\left(h_{t+1}, x_{t+1}\right)}{\partial x_{t+1}}=\frac{v^{\prime}\left(d\left(x_{t}\right)\right)-w^{\prime}\left(c\left(x_{t}\right)\right)-\beta \delta \frac{\partial V\left(h_{t+1}, x_{t+1}\right)}{\partial h_{t+1}} \cdot h^{\prime}\left(c_{t}\right)}{\delta z_{t+1} \cdot h^{\prime}\left(c_{t}\right)} .
$$

Combining (A.5) and (A.6), and using $\partial V\left(h_{t+1}, x_{t+1}\right) / \partial h_{t+1}=1$, we obtain the Euler equation (9).

\section{Proof of Proposition 5}

Insert $\tilde{z}$ from (7) and $z$ from (12) in (18) and (19) and define the elasticity of health with respect to healthy consumption at the first-best value by $\varepsilon=h^{\prime}\left(c^{*}\right) c^{*} / h\left(c^{*}\right)$. It then follows that for all $0<\beta, \delta<1$

$$
T_{\beta}\{\lesseqgtr\} \widetilde{T}_{\beta} \Longleftrightarrow \frac{\beta v^{\prime}\left(d^{*}\right)}{\beta v^{\prime}\left(d^{*}\right)+(1-\beta) \delta h^{\prime}\left(c^{*}\right) c^{* \prime}(y)}\{\lesseqgtr\} \varepsilon[1-\delta(1-\beta)]
$$

We denote the left-hand side of (A.7) by $\Theta(\beta)$ and the right-hand side by $\widetilde{\Theta}(\beta)$.

To evaluate $\Theta(\beta)\{\lesseqgtr\} \widetilde{\Theta}(\beta)$ we collect several properties of these functions. The boundary behavior at $\beta \rightarrow 0$ is given by

$$
\begin{aligned}
& \lim _{\beta \rightarrow 0} \Theta(\beta)=\left\{\begin{array}{lll}
0 & \text { if } & c^{* \prime}(y)>0 \\
1 & \text { if } & c^{* \prime}(y)=0,
\end{array}\right. \\
& \lim _{\beta \rightarrow 0} \widetilde{\Theta}(\beta)=\varepsilon(1-\delta)
\end{aligned}
$$

where in the last line of (A.8) we use L'Hôpital's rule. At $\beta \rightarrow 1$ we find

$$
\begin{aligned}
& \lim _{\beta \rightarrow 1} \Theta(\beta)=1 . \\
& \lim _{\beta \rightarrow 1} \widetilde{\Theta}(\beta)=\varepsilon
\end{aligned}
$$


Computing the derivatives yields

$$
\begin{aligned}
\Theta^{\prime}(\beta) & =\frac{\delta h^{\prime}\left(c^{*}\right) c^{* \prime}(y) v^{\prime}\left(d^{*}\right)}{\left[\beta v^{\prime}\left(d^{*}\right)+(1-\beta) \delta h^{\prime}\left(c^{*}\right) c^{* \prime}(y)\right]^{2}} \geq 0 \\
\widetilde{\Theta}^{\prime}(\beta) & =\delta \varepsilon>0
\end{aligned}
$$

Since $v^{\prime}\left(d^{*}\right)>\delta h^{\prime}\left(c^{*}\right) c^{* \prime}(y)$, we have $\Theta^{\prime \prime}(\beta) \leq 0$, with strict inequality if $c^{* \prime}(y)>0$.

Consider first $c^{* \prime}(y)=0$. According to (A.8), (A.10) and (A.12) it follows that $\Theta(\beta)=1$ for all $0<\beta<1$. From (A.11) and (A.13) we have $\widetilde{\Theta}(\beta)<\varepsilon$ for all $0<\beta<1$. Since $\varepsilon \leq 1$ this implies $\Theta(\beta)>\widetilde{\Theta}(\beta)$ for all $0<\beta<1$. Hence the claim is true for $\hat{\beta}=0$.

Consider now $c^{* \prime}(y)>0$ and assume first that $\varepsilon<1$. From (A.8) and (A.9) it holds $\Theta(\beta)<\widetilde{\Theta}(\beta)$ for $\beta$ close to zero. From (A.10) and (A.11) one has $\Theta(\beta)>\widetilde{\Theta}(\beta)$ for $\beta$ close to one. Hence there is an odd number of intersections of the functions $\Theta(\beta)$ and $\widetilde{\Theta}(\beta)$ in the interval $(0,1)$. Since $\Theta^{\prime \prime}(\beta)<0$ and $\widetilde{\Theta}^{\prime \prime}(\beta)=0$ there can be at most two such intersections. Altogether, we conclude that there is a unique intersection $\hat{\beta} \in(0,1)$ such that $\Theta(\hat{\beta})=\widetilde{\Theta}(\hat{\beta})$. For $\beta<\hat{\beta}(\beta>\hat{\beta})$, we have $\Theta(\beta)<\widetilde{\Theta}(\beta)(\Theta(\beta)>\widetilde{\Theta}(\beta))$, and hence $T_{\beta}<\widetilde{T}_{\beta}\left(T_{\beta}>\widetilde{T}_{\beta}\right)$ as claimed.

Finally we consider $c^{* \prime}(y)>0$ and $\varepsilon=1$. From (A.8) and (A.9) one sees again $\Theta(\beta)<\widetilde{\Theta}(\beta)$ for $\beta$ close to zero. From (A.10) and (A.11) one obtains $\lim _{\beta \rightarrow 1} \Theta(\beta)=$ $\lim _{\beta \rightarrow 1} \widetilde{\Theta}(\beta)$. As before, since $\Theta(\beta)$ is strictly concave and $\widetilde{\Theta}(\beta)$ is linear, there can be at most one intersection of both functions within the interval $(0,1)$. If such an intersection exists it is $\hat{\beta}$ as claimed in the proposition. Otherwise $\hat{\beta}=1$ and $T(\beta)<\widetilde{T}(\beta)$ for all $0<\beta<1$. Q.E.D. 


\section{References}

Angeletos, G.-M., Laibson, D., Repetto, A., Tobacman, J., and Weinberg, S. (2001). The hyperbolic consumption model: Calibration, simulation, and empirical evaluation. Journal of Economic Perspectives, 15(3):47-68.

Aronsson, T. and Thunström, L. (2008). A note on optimal paternalism and health capital subsidies. Economics Letters, 101(3):241 - 242.

Bartlett, S., Jacob, K., and Lauren, O. (2014). Evaluation of the healthy incentives pilot (HIP): Final report. Prepared by Abt Associates for the U.S. Department of Agriculture, Food and Nutrition Service.

Becker, G. S. and Murphy, K. M. (1988). A theory of rational addiction. Journal of Political Economy, 96(4):675-700.

Brezis, M. and Marans, R. (2010). Do people support sin taxes? A population survey of attitudes. World Medical and Health Policy, 2(4):33-43.

Business Roundtable (2007). Doing well through wellness: 2006-07 survey of wellness programs at business roundtable member companies. Retrieved 15 December 2015.

Cremer, H., De Donder, P., Maldonado, D., and Pestieau, P. (2012). Taxing sin goods and subsidizing health care. The Scandinavian Journal of Economics, 114(1):101123 .

Diamond, P. and Köszegi, B. (2003). Quasi-hyperbolic discounting and retirement. Journal of Public Economics, 87(910):1839 - 1872.

European Commission (2015). Evaluation of the European school fruit scheme. Retrieved 11 February 2015.

French, S. A., Jeffery, R. W., Story, M., Breitlow, K. K., Baxter, J. S., Hannan, P., and Snyder, M. P. (2001). Pricing and promotion effects on low-fat vending snack purchases: The CHIPS study. American Journal of Public Health, 91(1):112-117.

Gruber, J. and Köszegi, B. (2001). Is addiction "rational"? Theory and evidence. The Quarterly Journal of Economics, 116(4):1261-1303.

Gruber, J. and Köszegi, B. (2004). Tax incidence when individuals are time-inconsistent: The case of cigarette excise taxes. Journal of Public Economics, 88(910):1959 - 1987. 
Harris, C. and Laibson, D. (2001). Dynamic choices of hyperbolic consumers. Econometrica, 69(4):935-957.

Karp, L. (2005). Global warming and hyperbolic discounting. Journal of Public Economics, 89(23):261 - 282.

Laibson, D. (1994). Essays in hyperbolic discounting. Ph.D. dissertation.

Laibson, D. (1997). Golden eggs and hyperbolic discounting. The Quarterly Journal of Economics, 112(2):443-478.

Laibson, D. (1998). Life-cycle consumption and hyperbolic discount functions. European Economic Review, 42(35):861 - 871.

O’Donoghue, T. and Rabin, M. (1999). Incentives for procrastinators. The Quarterly Journal of Economics, 114(3):769-816.

O’Donoghue, T. and Rabin, M. (2003). Studying optimal paternalism, illustrated by a model of sin taxes. American Economic Review, 93(2):186-191.

O’Donoghue, T. and Rabin, M. (2006). Optimal sin taxes. Journal of Public Economics, 90(1011):1825 - 1849 .

Powell, L. M., Chriqui, J. F., Khan, T., Wada, R., and Chaloupka, F. J. (2013). Assessing the potential effectiveness of food and beverage taxes and subsidies for improving public health: A systematic review of prices, demand and body weight outcomes. Obesity Reviews, 14(2):110-128.

Volpp, K. G., John, L., Troxel, A. B., Norton, L., Fassbender, J., and Loewenstein, G. (2008). Financial incentive-based approaches for weight loss: A randomized trial. JAMA, 300(22):2631-2637.

Volpp, K. G., Troxel, A. B., Pauly, M. V., Glick, H. A., Puig, A., Asch, D. A., Galvin, R., Zhu, J., Wan, F., DeGuzman, J., Corbett, E., Weiner, J., and Audrain-McGovern, J. (2009). A randomized, controlled trial of financial incentives for smoking cessation. New England Journal of Medicine, 360(7):699-709. PMID: 19213683. 